\title{
The snow leopard in Xinjiang, China
}

\section{George B. Schaller, Li Hong, Talipu, Ren Junrang and Qiu Mingjiang}

Snow leopards live in the mountains of Central Asia, their range stretching from Afghanistan to Lake Baikal and eastern Tibet. They are endangered throughout their range, being hunted as predators of man's livestock and for their skin. Much of the snow leopard's range lies in China, but not enough is known about its status there for effective conservation. As part of a project to assess China's high-altitude wildlife resources the authors conducted a survey in Xinjiang-a vast arid region of deserts and mountains. Although the snow leopard and other wildlife have declined steeply in Xinjiang in recent decades, the cat still persists and one area has the potential to become one of the best refuges for the species in its entire range. Its future in Xinjiang, however, depends on well-protected reserves, enforcement of regulations against killing the animal, and proper management of the prey species.

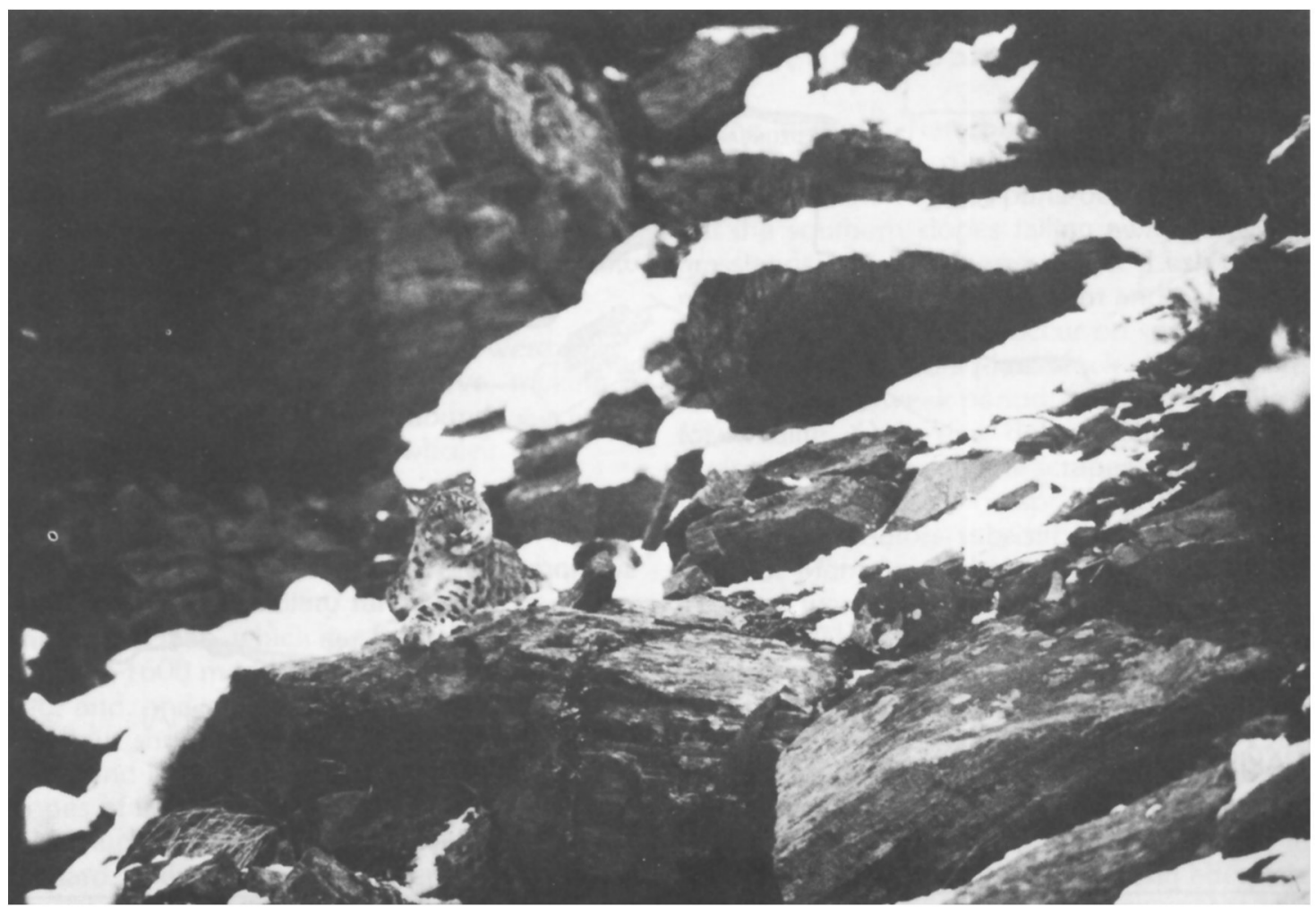

A female snow leopard in the wild (George Schaller). 
The snow leopard Panthera uncia has a wide distribution in Western China, its geographical range including the autonomous regions of Xinjiang and Tibet and the provinces of Sichuan, Gansu, Inner Mongolia and Qinghai. Although much of the snow leopard's total range lies within China, little has been published about the species in that country. Except for a paper by Liao (1985) on distribution of snow leopard in Qinghai, and one by Schaller et al. (1988) on the status of the cat in Qinghai and Gansu, recent literature consists mainly of general comments and records of specimens collected (Zhou et al., 1985; Lin, 1985; Lian, 1986).

As part of a collaborative project to assess China's high-altitude wildlife resources, we worked in various parts of Xinjiang, a vast, arid region of deserts and mountains, during MayJune 1985, May-July 1986 and April-June 1987. Xinjiang is large ( 1.6 million sq $\mathrm{km}$ ) and so we limited intensive work to five sample areas, three in the Tian Shan (shan means 'mountain') and two in the Kunlun Shan (Figure 1). The Tian Shan with its subsidiary ranges stretches across Xinjiang from the USSR to Mongolia, and the Kunlun Shan traces the southern border, one branch becoming the Arjin Shan (Altun Tagh). We entered the mountains of each sample area by yak, horse, or camel, and then searched for snow leopard spoor on foot, looking particularly for characteristic scrapes, which the cats leave at the base of cliffs, on passes, and other conspicuous locations by raking their hindpaws on the ground. All scrapes and droppings were counted to provide a crude measure of abundance. Food

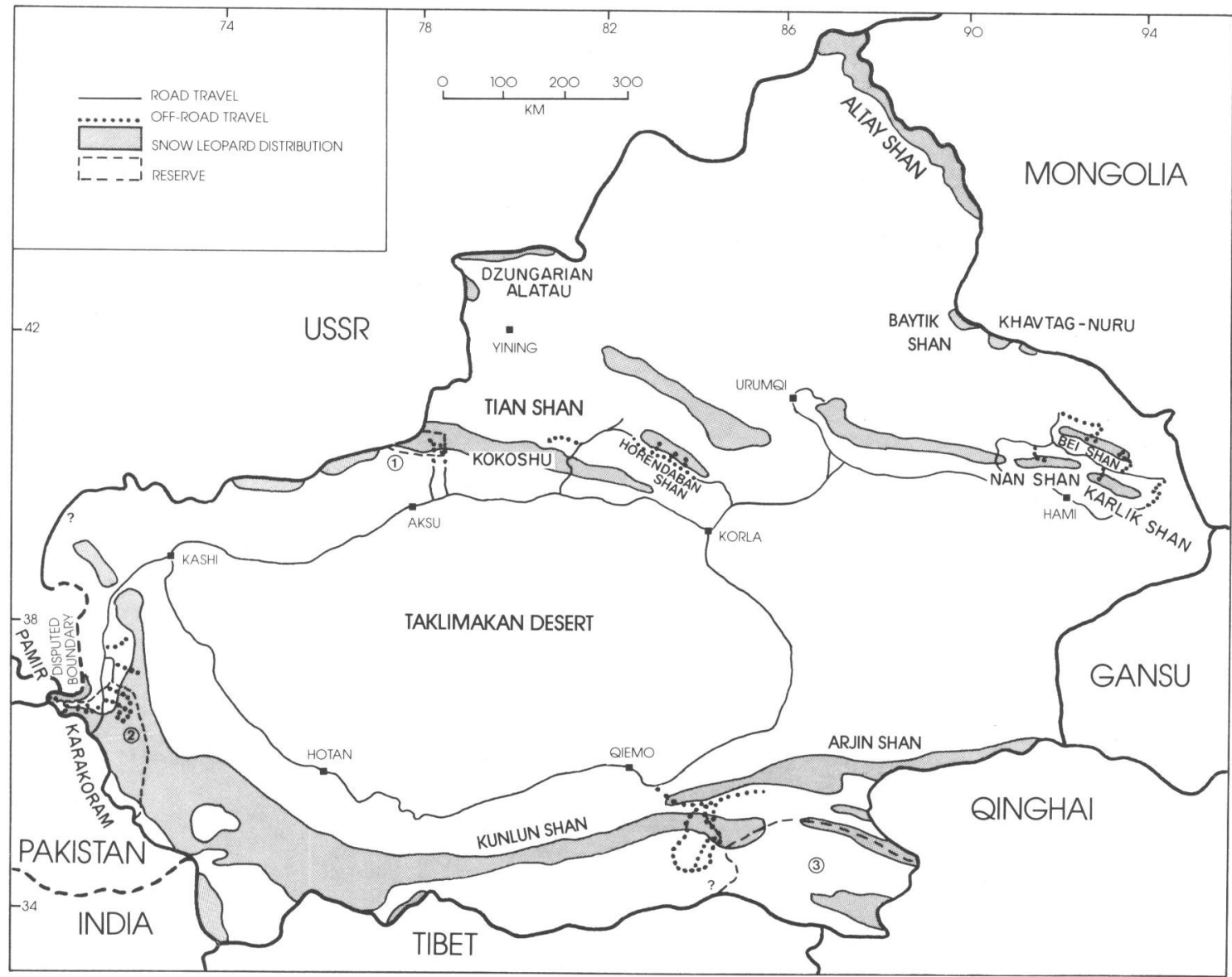

Figure 1. The distribution of snow leopard in the Xinjiang Uygur Autonomous Region. Travel routes are shown. The numbers indicate reserves: (1) Tomur Feng, (2) Taxkorgan and (3) Arjin Shan. 
habits of predators were determined by analysing contents of droppings. Prey remains were identified by the distinctive colour and texture of hair and the presence of claws, teeth and other material. In addition, local people and officials were queried about the snow leopard's status in nearby ranges. Counts of wild ungulates were made in certain areas to determine the abundance of potential snow leopard prey. Schaller et al. (1987, 1988) describe survey methods in detail.

\section{Distribution and status}

Snow leopards occur, or once occurred, in all major ranges of Xinjiang wherever there is suitable habitat in the form of broken terrain with cliffs (Jackson and Ahlborn, 1984) and an adequate amount of prey, mainly blue sheep Pseudois nayaur in the Kunlun and Arjin mountains and ibex Capra ibex elsewhere. In northern Xinjiang, an area we did not survey, snow leopards are found in the Altay Shan on both China's side of the border and on the USSR and Mongolian sides (Braden, 1982; Mallon, 1984). Further south, in the Dzungarian Alatau bordering the USSR, they are said to be close to extinction if not already gone; in the Baytik Shan, as well as further east on the small Khavtag-Nuru and Takhiyn-Shara-Nuru mountains, all bordering Mongolia, they apparently survive in low numbers (Zhirnov and Ilyinsky, 1986).

Two of the five areas we sampled were in reserves and one adjoined a reserve, making it possible that wildlife was more abundant in these areas than in the region as a whole.

\section{Tian Shan}

In the eastern Tian Shan, east of Urumqi, we checked three subsidiary ranges, the Bei, Nan, and Karlik Shan, which rise from the desert floor at about $1600 \mathrm{~m}$ to over $4000 \mathrm{~m}$. Although rugged, arid, and covered only sparsely with grass and low shrubs (except for patches of spruce Picea and larch Larix forest on the north-facing slopes of the Nan Shan) the area had, we were told, much wildlife until recently, including snow leopard, ibex and argali sheep Ovis ammon karelini. Some of the low-lying terrain bordering the desert did not look like typical snow leopard habitat, but, as noted by Zhirnov and Ilyinsky (1986) for southern Mongolia, "in the conditions of the Gobi Desert this predator is also adapted to foothills and even oases within true deserts. In Central Asia the snow leopard occupies the ecological niche of the leopard which is absent from this region'.

During 10 days in the field, no definite snow leopard spoor was found, although herdsmen in the Bei Shan reported that on rare occasions a domestic animal is killed by a cat, and wolves Canis lupus also take livestock. An intensive search of a 250-sq-km mountain block in the Bei Shan revealed just six ibex. Old horns of ibex and argali around herdsmen's huts indicated the fate of many animals. A few goitered gazelle Gazella subgutturosa persisted along the base of the mountains, and red deer Cervus elaphus songaricus survived in moderate numbers in the forests of the Nan Shan, protected there because the sale of cast antlers, used for medicinal purposes, brings income to the government. Wildlife elsewhere in the eastern Tian Shan also appears to be scarce (Rowell, 1983).

In the western Tian Shan, we surveyed the Horendaban Shan, a subsidiary range that rises to $4600 \mathrm{~m}$, the highest parts being precipitous but the southern slopes falling away to rolling grasslands cut by deep valleys. Lush alpine meadows extend up to $3300 \mathrm{~m}$ and patches of spruce and birch Betula occur on some slopes. We selected a $750-\mathrm{sq}-\mathrm{km}$ block of mountains and during a 2-week period surveyed all valleys for wildlife. Only one definite snow leopard scrape and three probable scrapes, all old, were found. By contrast, wolf spoor was quite common, the predators subsisting mainly on ibex, marmot Marmota bobac, and livestock (Table 1). Ibex were moderately abundant, our tally including 716 animals in 48 herds. This count was probably a minimum, for at the time of our visit in May some females had retreated into crags to give birth. The first newborn of the 1986 season was observed on 25 May. The ratio of yearlings (1-2 years old) to adult females was $46: 100$ and that of young (up to 1 year old) to adult females was 55:100, indicating adequate reproduction and survival. We also counted 63 argali, but only three red deer tracks were noted. 
Taking into account that a number of ibex were overlooked, total ungulate density in the survey block was about 1.0-1.3 animals per sq km.

The far western Tian Shan may retain more snow leopards than other parts of the range. After visiting the Kokosu valley in 1926, Morden (1927) wrote: 'We saw numbers of snow leopard tracks and one of our men claimed to have seen one. They seemed plentiful enough ...'We were told that, as recently as the winter of 1985-1986, local people killed a total of 12 snow leopards south of the Kokosu, and a year earlier two men killed 11 snow leopards to the north-west of the town of Aksu.

The highest mountains in the Tian Shan, with several peaks exceeding $6500 \mathrm{~m}$, were incorporated into the $3000-\mathrm{sq}-\mathrm{km}$ Tomur Feng reserve in 1986, and we made a 12-day survey of two major valleys in the reserve the following year. The lower slopes of the mountains, below 3000 $\mathrm{m}$, have alpine grassland broken by stands of spruce and birch, and cottonwood Populus grows along streams. However, over half the reserve consists of barren peaks and cliffs and huge rubble-covered glaciers. In the Datrang drainage, about $475 \mathrm{sq} \mathrm{km}$ in size, we found no snow leopard spoor, and, according to herdsmen, cats seldom visit the valley now. Further east, we sampled only the lower $40 \mathrm{~km}$ of the Mazat valley and several of its long tributary valleys. Snow leopard signs, comprising nine droppings and 20 scrapes, were noted in the upper valley above $2200 \mathrm{~m}$. The drop- pings contained ibex and an unusual amount of vegetation, primarily Tamarix twigs (Table 1). The wolves in the area also fed mainly on ibex supplemented by hare Lepus capensis. Marmots, which represent an important summer food source (they hibernate from October through March) in the Horendaban Shan, as well as in the Kunlun Shan, were for unknown reasons absent from these valleys. Snow leopards were scarce in Tomur Feng, and we doubt that more than 15 animals use the reserve.

A total of 211 ibex were observed in the Datrang valley, most of them at low elevations at the time of our visit in early May, and we estimate that 300-350 occur in the drainage, or 0.7 animals per sq $\mathrm{km}$. In the Mazat valley we tallied 415 ibex. The ratio of yearlings to adult females was 29:100 and that of young to adult females was 54:100 in the two drainages, a similar ratio of young to that found in the Horendaban Shan the previous year but a lower yearling ratio. No signs of red deer were noted even though this species was once apparently common in the lower Datrang valley.

\section{Kunlun Shan}

In the west where the Kunlun Shan adjoins the Karakoram and Pamirs is the Taxkorgan Reserve, about $14,000 \mathrm{sq} \mathrm{km}$ of arid mountains with most of the terrain lying above $3500 \mathrm{~m}$ and much above the limit of vegetation at $4500 \mathrm{~m}$. Our 2 months of survey in the western half of the reserve are summarized in Schaller et al.

Table 1. Food items in snow leopard and wolf droppings, expressed as per cent of total content in sample

\begin{tabular}{|c|c|c|c|c|c|}
\hline \multirow[b]{2}{*}{ Fooditem } & \multicolumn{2}{|l|}{ Snow leopard } & \multicolumn{3}{|l|}{ Wolf } \\
\hline & $\begin{array}{l}\text { Tomur Feng } \\
(n=19)\end{array}$ & $\begin{array}{l}\text { Taxkorgan } \\
(n=72)\end{array}$ & $\begin{array}{l}\text { Tomur Feng } \\
(n=18)\end{array}$ & $\begin{array}{l}\text { Horendaban } \\
(n=95)\end{array}$ & $\begin{array}{l}\text { East Kunlun } \\
(n=115)\end{array}$ \\
\hline Ibex & 71.1 & 4.2 & 90.6 & 63.1 & - \\
\hline Blue sheep & - & 59.9 & - & - & 2.6 \\
\hline Argali & - & - & - & 2.1 & 2.6 \\
\hline Tibetan antelope & - & - & - & - & 9.6 \\
\hline Livestock & - & 4.9 & - & 5.2 & - \\
\hline Marmot & - & 29.1 & - & 21.6 & 80.0 \\
\hline Hare & - & 1.0 & 5.6 & - & 4.3 \\
\hline Small rodent & - & - & - & 1.1 & Trace \\
\hline Unidentified hair & - & - & - & 3.2 & - \\
\hline Vegetation & 28.9 & 0.7 & 3.9 & 0.6 & Trace \\
\hline Other & - & 0.2 & - & 3.2 & 0.9 \\
\hline
\end{tabular}




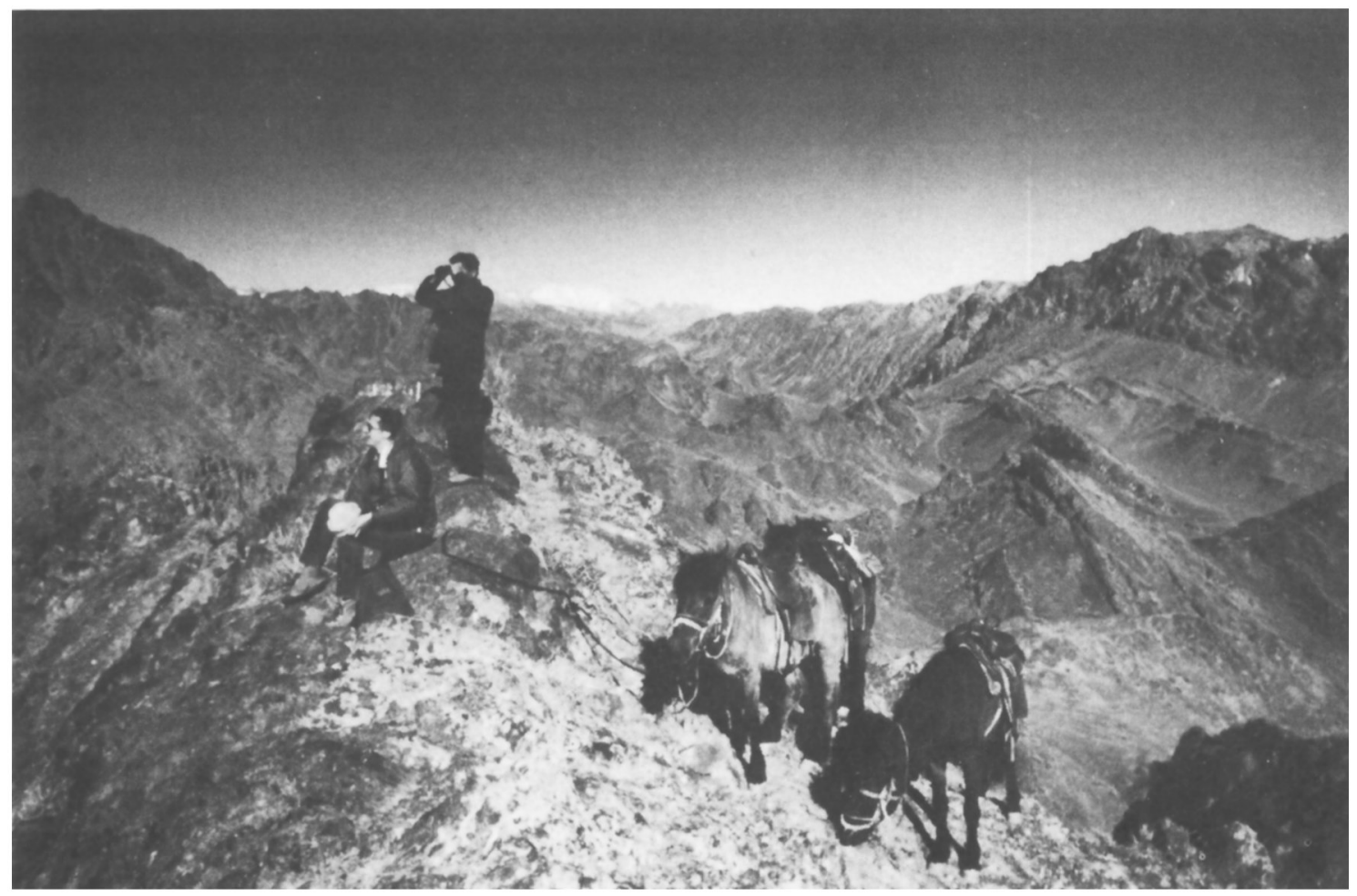

Ibex, argali and snow leopard were once common in the low, rugged hills of the Bei Shan in the eastern Tian Shan (George Schaller).

(1987). Snow leopards were rare, except in several valleys of the Mariang commune, and the total estimated population in the reserve was 50-75. Their prey consisted mainly of marmot $M$. caudata and blue sheep (Table 1). Of the ungulates in the reserve, ibex and a few Marco Polo sheep O. a. poli occur in the western part, and blue sheep-the most abundant ungulatein the eastern and south-eastern parts, their range overlapping slightly with that of the ecologically similar ibex. Counts in selected mountain blocks totalling $1445 \mathrm{sq} \mathrm{km}$ revealed an average density of 0.34 ungulates per sq $\mathrm{km}$.

Between the western end of the Kunlun Shan and the eastern part where it forks, a distance of about $1000 \mathrm{~km}$, nothing is known about the status of snow leopard. Travelling from India, Roosevelt and Roosevelt (1926) noted snow leopard tracks in the Kunlun, and Prejevalsky (1879) commented that the cats were 'very rare' in the Arjin Shan.

Snow leopards in Xinjiang
We surveyed the Arjin Shan and adjoining Kunlun Shan for nearly 3 weeks, travelling across the ranges on to the Tibetan Plateau (Figure 1). The terrain, most of it above $3500 \mathrm{~m}$, consists of steep hills, rolling plains, and broad valleys broken by massive peaks and bisected by gorges. Vegetation is sparse in this desert environment, mainly scattered shrubs such as Ceratoides and Salsola, and narrow bands of grass along seepages. Herdsmen told us that snow leopards are rare in these mountains, and indeed we failed to find signs of their presence. Wolves, by contrast, were quite common, especially on the plateau, their main prey consisting of marmot $M$. himalayana and Tibetan antelope Pantholops hodgsoni. There was little wildlife in the mountains. For example, during a 6-day traverse of the Kunlun by camel we observed two wild yak Bos grunniens, 11 argali $O$. $a$. hodgsoni, 12 Tibetan antelope, 25 kiang Equus hemionus kiang, and 16 blue sheep, an ungulate density of about 0.2 animals per sq $\mathrm{km}$. By 201 


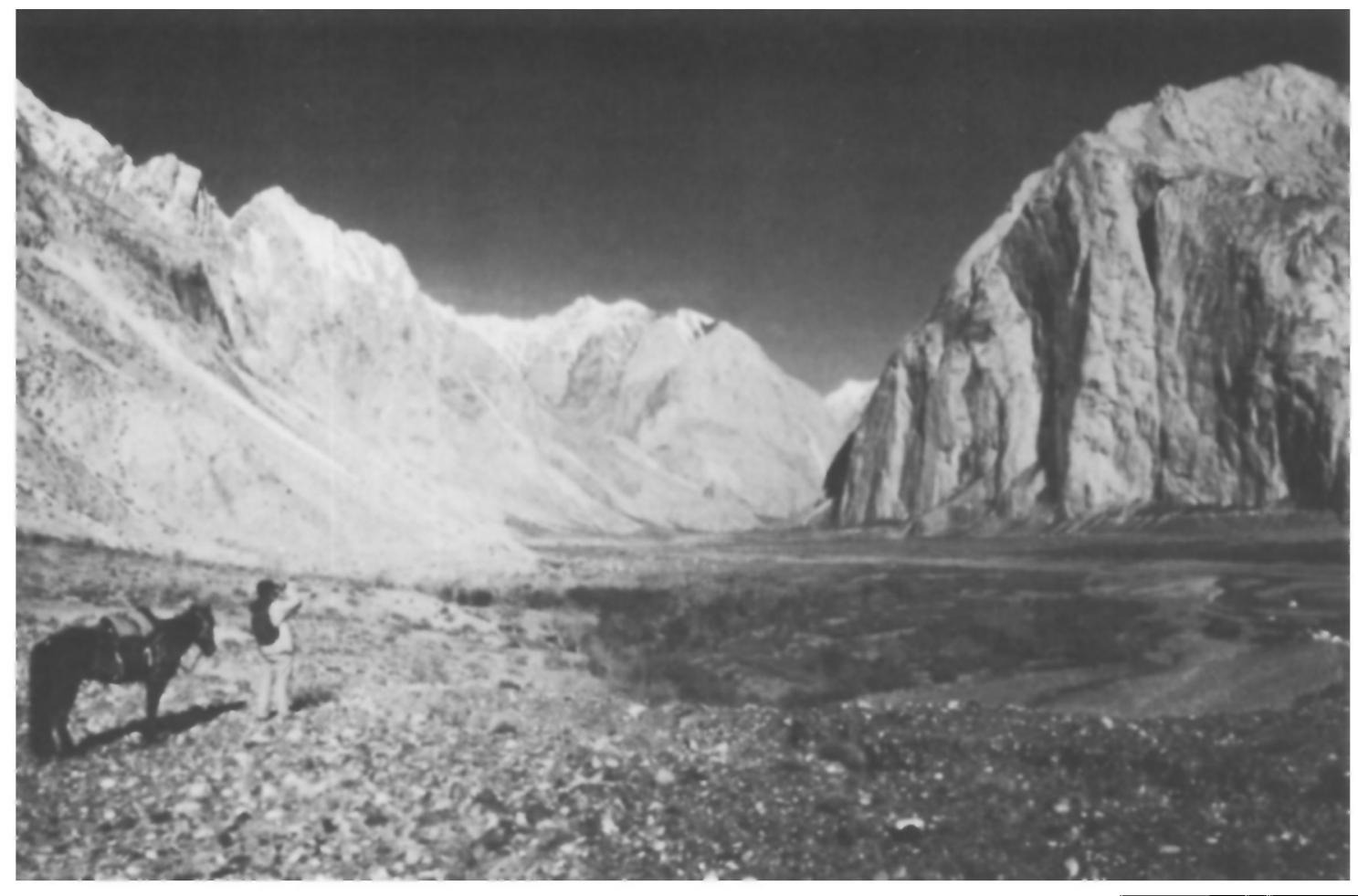

The Mazat Valley in the Tomur Feng Reserve, western Tian Shan. Just before this photograph was taken a snow leopard had walked near the base of the high cliff on the right (George Schaller).

contrast, on the adjoining plateau the density was $0.9-1.9$ per sq $\mathrm{km}$, depending on habitat, principally Tibetan antelope.

The 45,000-sq-km Arjin Shan Reserve, established in 1983, lies just east of the survey area. Much of the reserve consists of plains and hills, habitat unsuitable for snow leopard, and the cats are consequently rare, most of them found in the south-eastern corner ( $\mathrm{Gu}$ Zhenquin, pers. comm.).

The total range of snow leopard in Xinjiang encompasses about $170,000 \mathrm{sq} \mathrm{km}$ or 10.6 per cent of the area. Within this range the species occurs at low densities primarily because it has been decimated by hunting. Although sparse vegetation in parts of the Kunlun Shan and similar arid environments would normally support few animals, hunting has further depressed both predator and prey numbers. In several ranges the snow leopard is now either extinct or almost so, as is its prey, and in the other areas only a few local populations of moderate density per202 sist. Snow leopards were rare in two areas of the western Tian Shan yet ibex were quite common, showing that prey abundance may not reflect predator status. Parts of the western Tian Shan and western Kunlun, specifically the Mariang area in the Taxkorgan Reserve, retained viable cat populations and others no doubt exist in the Kunlun. We are unable to provide a population estimate for Xinjiang except to note that there may be no more than 750 .

\section{Conservation}

On reading accounts of travellers (Prschewalski, 1884; Carruthers, 1914; Morden, 1927) and talking to local people, it is evident that wildlife was once abundant in parts of Xinjiang. The policies of the Great Leap Forward in 1958 caused agricultural production to drop for several years and many animals were slaughtered for food. During the 1966-1976 Cultural Revolution, conservation directives were ignored, and some county governments promoted inten-

Oryx Vol 22 No 4, October 1988 


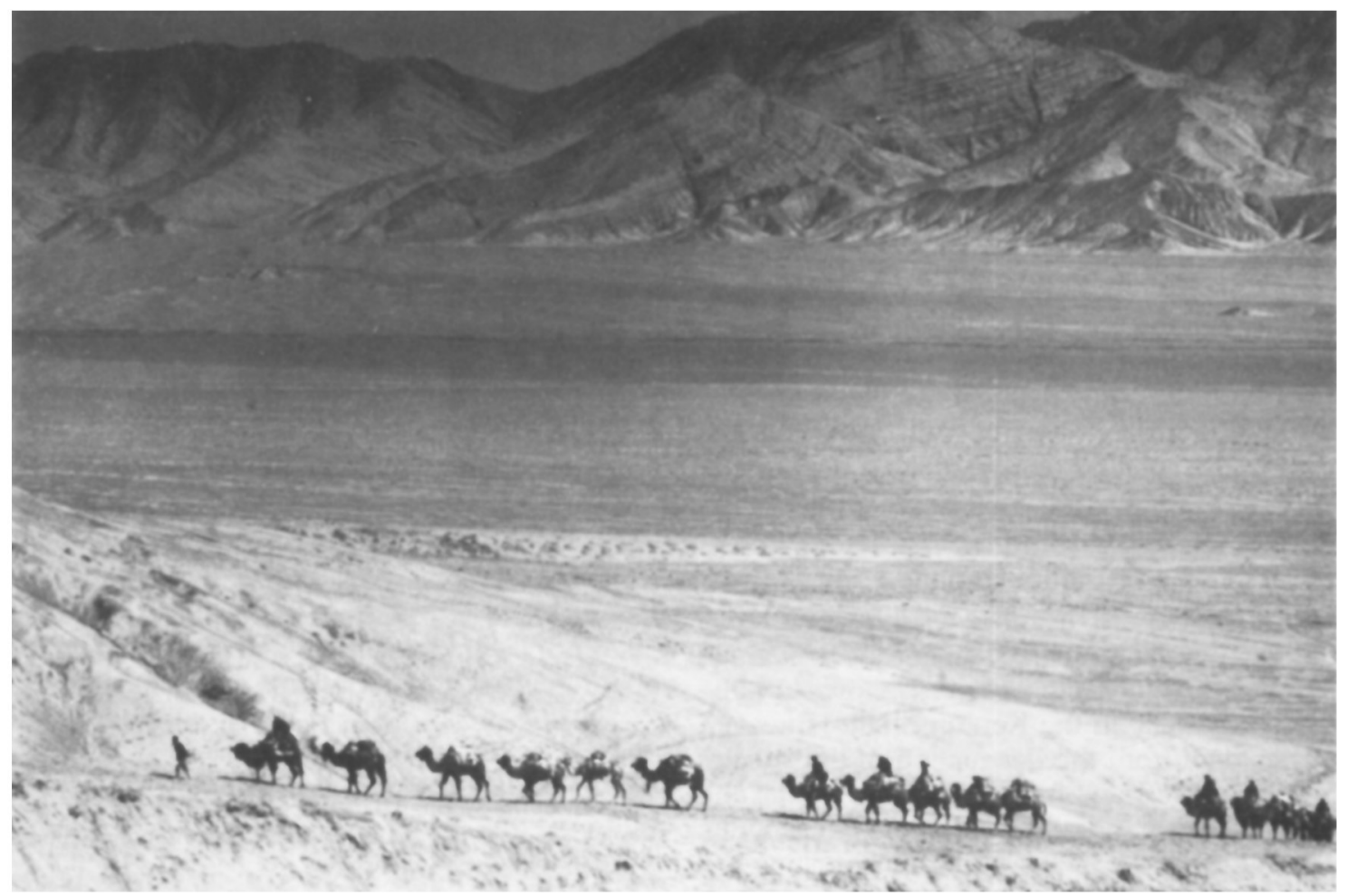

The survey team's camel caravan, crossing the barren Kunlun Shan on the way to the Tibetan Plateau

(George Schaller).

sive commercial hunting, with, for example, trainloads of ibex, argali and other carcasses being shipped east from the Tian Shan. Although the government has in recent years actively promoted conservation measures, enforcement of regulations is difficult, and hunting with rifle and steel trap remains widespread. Consequently, wildlife in most areas continues to decline and vast tracts are already devoid of formerly abundant species such as gazelle and argali.

As a predator on livestock, the snow leopard has earned the enmity of herdsmen, and until the mid-1960s it was systematically destroyed. From 1955 to 1965 an average of 30 snow leopard skins were sold annually to the government in the Yining (lli) prefecture in western Tian Shan; after a peak of 135 skins in 1965 there was a drastic decline with some recent years producing not even one (Zhang, 1985). In spite of receiving complete legal protection in 1983, snow leopards continue to be hunted and skins continue to be sold on the open market. Except Snow leopards in Xinjiang for some remote parts of the Kunlun, herdsmen with their livestock penetrate the mountains at least seasonally wherever there is pasture. Losses of livestock to snow leopard are generally small and sporadic - the wolf is considered to be more destructive-but in a few localities the impact may be considerable. For instance, during one sample year each family in the Mariang commune in the Taxkorgan Reserve lost an average of 3.6 head of livestock mostly to snow leopard and a few to wolf (Schaller et al., 1987). However, predation can be ascribed partly to scarcity of the snow leopard's natural prey, even marmots being locally exterminated for their pelts and because they are said to compete with domestic animals for grass, and to lax herding practices, livestock often being left unguarded.

Xinjiang has three reserves, comprising 62,000 $\mathrm{sq} \mathrm{km}$, in which snow leopard occur. However, the total number of cats in these reserves is small, probably fewer than 120 , and their future remains insecure. The Taxkorgan Reserve contains 
about 7750 people and 70,000 domestic animals. The viability of this reserve will depend on the willingness of the Kirgiz and Tajik peoples there to coexist with wildlife, and meaningful concessions on their part will depend on how well a management programme to restrict hunting, fuelwood collecting, and livestock grazing reflects their needs and aspirations. The Tomur Feng Reserve is grazed by livestock only in summer. It needs enlargement, anti-poaching patrols and limits on the amount of livestock. The western Tian Shan could become the best refuge for snow leopard in Xinjiang and, including the USSR side of the border (Koshkarev, 1984), one of the best in the cat's range as a whole. Much of the Arjin Shan Reserve remains devoid of herdsmen and livestock.

The snow leopard, as other wildlife, has greatly decreased in Xinjiang in recent decades. Although numbers are low, the cat persists over a large area, especially in the Kunlun Shan. However, it is evident from the destruction of the species in parts of the Tian Shan that remote habitat and a sparse human population do not offer security. The future of the snow leopard in Xinjiang will depend ultimately on large well-protected reserves, enforcement of regulations against killing the cat, and proper management of prey animals.

\section{Acknowledgments}

This work is the result of a collaborative effort between Wildlife Conservation International (a division of the New York Zoological Society), the China Wildlife Conservation Association, the Ministry of Forestry, Beijing, and the Forest Bureau, Xinjiang. Many officials assisted us in Beijing, Urumqi, Aksu, Korla, Heijing, Kashi, Taxkorgan, Hami, Barkol, Yiwu, Qiemo and elsewhere, and we want to express our gratitude for their efforts and hospitality, noting especially the help of Wang Menghu and Liang Guodeng. Tawand, Lu Hua, Gu Zhenqin, and Wang Haibin assisted ably in the field.

\section{References}

Braden, K. 1982. The geographic distribution of snow leopards in the USSR: maps of areas of snow leopard habitation in the USSR. Int. Ped. Book of Snow Leopards, 3, 25-39. Helsinki Zoo, Finland.

Carruthers, D. 1914. Unknown Mongolia. J.B. Ljppincott, Philadelphia.
Jackson, R. and Ahlbom, G. 1984. A preliminary habitat suitability model for the snow leopard, Panthera uncia. Int. Ped. Book of Snow Leopards, 4, 43-52. Helsinki Zoo, Finland

Koshkarev, E. 1984. Characteristics of snow leopard (Uncia uncia) movements in the Tien Shan. Int. Ped. Book of Snow Leopards, 4, 15-21. Helsinki Zoo, Finland.

Lian Congqi. 1986. Wildlife of Xinjiang. Forestry Publishing House, Urumqi (in Chinese):

Liao Yanfa. 1985. The geographical distribution of ounces in Qinghai Province. Acta Theriologica Sinica, 5, 183188 (in Chinese).

Lin Yonglie. 1985. The mammals from Mt. Tuomuer areas in Tian Shan. In The Biology of Tomur Feng Region in Tian Shan, pp. 1-19. Xinjiang People's Publishing House, Urumqi (in Chinese).

Mallon, D. 1984. The snow leopard, Panthera uncia, in Mongolia. Int. Ped. Book of Snow Leopards, 4, 3-9. Helsinki Zoo, Finland

Morden, W. 1927. Across Asia's Snows and Deserts. G.P. Putnam's Sons, New York.

Prejevalsky (Przewalski), N. 1879. From Kulja across the Tian Shan to Lob Nor. Sampson Low, Marston, Searle, and Rivington, London.

Prschewalski (Przewalski), N. 1884. Reisen in Tibet am oberen Lauf des Gelben Flusses in den Jahren 1879 bis 1880 . Hermann Costenoble, Jena.

Roosevelt, T. and Roosevelt, K. 1926. East of the Sun and West of the Moon. Charles Scribner's Sons, London.

Rowell, G. 1983. Mountains of the Middle Kingdom. Sierra Club Books, San Francisco.

Schaller, G., Li Hong, Talipu, Lu Hua, Ren Junrang, Qiu Mingjiang and Wang Haibin. 1987. Status of large mammals in the Taxkorgan Reserve, Xinjiang, China. Biol Conserv. 42, 53-72.

Schaller, G., Ren Junrang and Qiu Mingjiang. 1988. Status of snow leopard in Qinghai and Gansu provinces, China. Biol. Conserv., in press.

Zhang Daming. 1985. The dynamics of a few animals during the last thirty years in Ili Prefecture, Xinjiang Uygur Autonomous Region. Acta Theriologica Sinica, 5, 56 (in Chinese).

Zhimov, L. and Ilyinsky, V. 1986. The Great Gobi National Park-a Refuge for Rare Animals of the Central Asian Deserts. Centre for International Projects, GKNT, Moscow.

Zhou Jiadi, Li Sihua and Gu Jinghe. 1985. The preliminary observation on the mammals in Kunlun-Altun Basin. Acta Theriologica Sinica, 5, 160 (in Chinese).

George B. Schaller, Wildlife Conservation Intemational, New York Zoological Society, Bronx Park, New York 10460, USA. Li Hong and Talipu, Forest Bureau, Urumqi, Xinjiang, China. Ren Junrang, Northwest Institute for Endangered Animals, Xian, Shaanxi, China.

Qiu Mingjiang, Wolong Natural Reserve, Sichuan, China. 